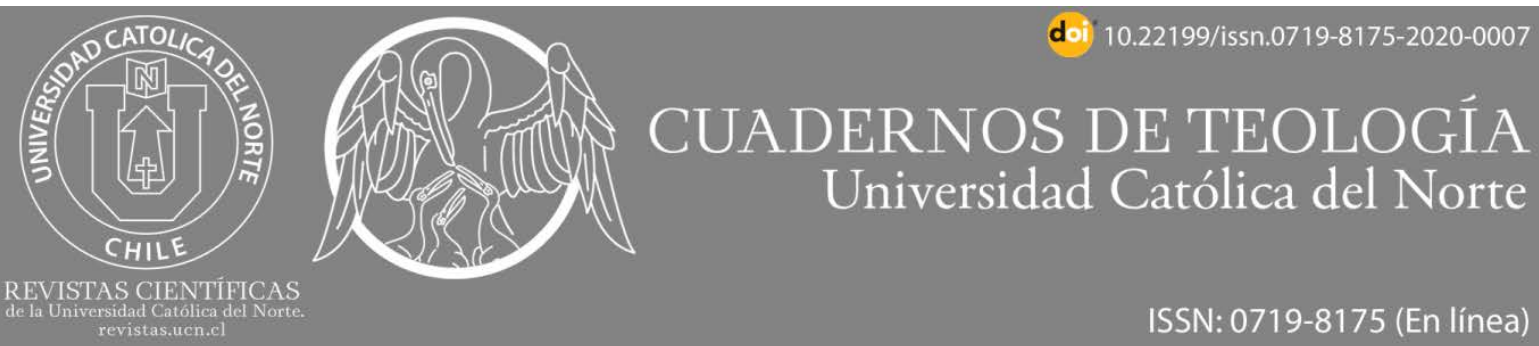

\title{
Razón poética, revelación y saber: aproximaciones al pensamiento religioso de María Zambrano
}

\section{Poetic reason, revelation and knowing: approaches to the religious thought of María Zambrano}

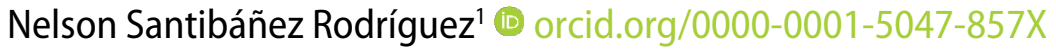 \\ 'Universidad Santo Tomás, La Serena, Chile. Profesor de Filosofía y religión. Estudiante de Magíster en Estudios \\ Latinoamericanos, U. de La Serena. \\ nelsonsantibanez@gmail.com \\ $(\mathrm{cc})$ BY
}

\begin{abstract}
Resumen:
Se pretende dar un acercamiento al pensamiento religioso de María Zambrano; para ello la metodología adoptada consistió en una revisión bibliográfica de las obras de la pensadora y de las de algunos de sus principales estudiosos y estudiosas. Producto de ello, inicialmente se desarrolla una aproximación general al fenómeno del lenguaje religioso, para enmarcar la forma en que la autora usó tal lenguaje; luego, se expone una semblanza biográfica de la pensadora como una forma de relevar sus fuentes formativas, sus ocupaciones intelectuales y sus opciones lingüísticas. Ambas secciones son propuestas por ser concebidas como contextos significativos para abordar su pensamiento. También, de forma transversal, se da cuenta de la crítica que Zambrano realiza a la tradición filosófica occidental. En específico, respecto de su pensamiento teologal se exponen con mayor detalle los conceptos de poesía, filosofía y, especialmente, de "razón poética", concebida ésta última como la noción con que la autora propone sintetizar poesía y razón, y a la cual le atribuye -en tanto saber poético- la capacidad de revelar el verdadero ser de las cosas y el sentido genuino de la existencia humana.
\end{abstract}

Palabras Clave: Filósofas españolas del siglo 20; Conocimiento; Poesía; Filosofía; Autocomunicación de Dios.

\section{Abstract:}

It is intended to give an approach to the religious thought of María Zambrano. To achieve the objective, the methodology consisted of a bibliographic review of the works of the thinker and some of her main scholars. As a result, initially a general approach to the phenomenon of religious language is developed, to frame the way in which the author used said language. A biographical sketch of the thinker is also exposed to reveal his formative sources, his intellectual occupations and his linguistic options. It is proposed that both sections be conceived as meaningful contexts to address your thinking. In addition, in a transversal way, she realizes the criticism that Zambrano makes of the western philosophical tradition. Specifically, regarding her theological thinking, the concepts of poetry, philosophy and "poetic reason" are exposed in greater detail, the latter conceived as the notion with which the author proposes to synthesize poetry and reason, and to which she attributes - meanwhile Poetic Knowledge: the ability to reveal the true being of things and the genuine meaning of human existence

Keywords: Spanish philosophers of the 20th century; Knowledge; Poetry; God's self communication. 
¡Existen demasiadas cosas entre el cielo y la tierra con las cuales sólo los poetas se han permitido soñar! $Y$, sobre todo, encima del cielo: ¡Pues todos los dioses son un símbolo de poetas, un amaño de poetas!

Nietzsche - Así Habló Zaratustra

\section{Introducción al lenguaje religioso}

Tradicionalmente, y de manera general, una de las formas de clasificar los distintos tipos de lenguajes es atendiendo a su contenido específico; en este sentido, por ejemplo, se puede postular la existencia de un tipo de lenguaje político, filosófico, anárquico, científico, etc. (Acero Fernández, 1985; Chomsky, 1973; Eco, 1992). Según esta manera de catalogar, el lenguaje religioso sería "aquel en cuyo contenido se emplea la palabra "Dios" o está en relación, directa o indirecta con esa palabra" (Conesa Ferrer y Nubiola Aguilar, 2012, p. 264). Esa forma de generar taxonomías tiene la dificultad de desconectar parcialmente los distintos tipos de lenguajes, como si éstos fueran entidades lingüísticas independientes, que no se conciernen entre sí; se olvida en ello la obviedad de que cada tipo de lenguaje tiene, al menos, una dimensión que no es auto referente si no que más bien se siente convocada a ser comprensible para quienes le reciben, más allá de su propia especificidad discursiva (Habermas, 1989).

Por ello, para acentuar la ineludible implicación existente entre diversos discursos, en vez de hablar de tipos de lenguaje -desde una perspectiva pragmática (Escandell Vidal, 2006) - se propone hablar de "usos" específicos; por ejemplo, hablar de un "uso político" o de un "uso filosófico" del lenguaje (Conesa Ferrer y Nubiola Aguilar, 2012). En particular, parece posible establecer que existe un "uso religioso" del lenguaje, en el entendido que ese uso específico es una proyección de la capacidad de significación del que podemos denominar "el lenguaje cotidiano", es decir, se concibe que todos los usos que sean posibles de establecer son, en mayor o menor medida, ampliaciones y especificaciones del uso ordinario del lenguaje.

Además, a partir de la teoría de los juegos del lenguaje desarrollada por Wittgenstein en su obra Investigaciones filosóficas (Wittgenstein, 2016), tales usos específicos pueden ser concebidos como un cierto "juego" del lenguaje; aunque para ello, hay que aceptar que la noción de "juego" es difícil de definir con exactitud y, si bien hay antecedentes de comparaciones entre el lenguaje y ciertos juegos -por ejemplo, con el ajedrez-, hay que admitir que la noción de "juego" wittgensteineana, junto a su dimensión explicativa, tiene una buena porción de pura expresividad (Cordua Sommer, 1997, pp. 265266).

En relación al uso específicamente religioso, este puede ser concebido como un juego de lenguaje que se despliega en tres modos diferentes de "jugar": en primer lugar, en uno que cabe llamar "uso en modo religioso", el cual puede ser caracterizado como el juego lingüístico que utiliza quien cree para referir o expresar sus creencias y se caracterizaría por ser usado eminentemente en clave existencial; por otra parte, estaría el "uso en modo 
teológico", el cual puede ser descrito como el juego lingüístico que utilizan, las y los creyentes, en la reflexión preferentemente intelectual de su fe (Conesa Ferrer y Nubiola Aguilar, 2012); y en tercer lugar, es posible concebir un "uso en modo teologal", el que puede ser señalado como el uso en el que quien habla pretende mantenerse en un campo lingüístico eminentemente filosófico para referirse a la divinidad -independientemente si tal pretensión es posible de alcanzar en una elocución particular-; desplegando en ello un discurso que podemos caracterizar como pre-teológico, aunque en algunas proposiciones determinadas pueda llegar a colaborar en el desarrollo reflexivo específicamente teológico (Correa Schnake, 2012, p. 27). Adelantamos que será en este tercer modo de uso, en el teologal, donde situamos buena parte de la obra de María Zambrano.

Los tres modos de uso señalados comportan, cada uno en su peculiaridad, el desafío de abordar lingüísticamente las características particulares de, al menos, dos elementos marcadamente polisémicos: el ser de Dios y el ser del sujeto hablante. Y es para superar este doble desafío, según Conesa Ferrer y Nubiola Aguilar (2012), que el lenguaje religioso tiende a utilizar "todos los recursos que la lengua pone a su disposición, especialmente los adverbios, los superlativos, los prefijos, las negaciones, los circunloquios, etc." (p. 266). Ejemplo del "tono" otorgado a la expresión lingüística religiosa por el abundante, y hasta cierto punto inevitable, uso de los recursos de la lengua es la recurrencia al simbolismo y a la analogía para abordar el ser de Dios; el cual se percibe, al menos en un a priori lingüísticocomo inefable e imposible de abarcar; en esto, cabe apuntar que la expresión simbólica y analógica del lenguaje religioso tiende, paradójicamente, a revelar y a ocultar, a la misma vez, la realidad divina a la cual apunta.

Ese uso abundante de los recursos expresivos por parte del lenguaje religioso es el andamiaje -luego revestido de técnica y retórica- que se encuentra en la base de expresiones lingüísticas teologales que rondan la expresión poética; tal andamiaje también, ya en el contexto específico del pensamiento de María Zambrano, es el aparato amplificador del "timbre de voz" que resonará en la obra de la pensadora española, en general, y su propuesta de "razón poética", en particular (Zambrano, 2016, p. 15-26).

También, esa forma de expresividad exuberante nos enfrenta a la cuestión sobre cuándo una expresión puede ser considerada una expresión poética. Para abordar tal pregunta, cabe recordar la reflexión de Goodman, en el contexto general del arte, quien propuso que la pregunta fundamental ya no es ¿Qué es arte? (lo que aquí equivale a preguntar por ¿Qué es poesía?) sino que Goodman considera que la pregunta fundamental es ¿Cuándo algo es arte? (Goodman, 1990, pp. 87-88); esto supone un traslado desde un abordaje de tendencia esencialista a uno de naturaleza pragmática (Escandell Vidal, 2006), tal movimiento es lo subyace a la pregunta ¿Cuándo un uso del lenguaje puede ser considerado como una expresión poética?

Frente a esa interrogante, pensamos junto con Wittgenstein, que un uso específico deviene en expresión poética, en tanto juego de lenguaje, cuando se despliega de modo eminentemente expresivo y en mucha menor medida comunicativo. En ello, el pensador austriaco insiste que "no olvidemos que un poema, aun cuando esté compuesto en el lenguaje de la comunicación, no es utilizado en el juego del lenguaje de la comunicación" 
(Wittgenstein, 1997, p. 160), es decir, él considera que, en sentido estricto, una expresión poética siempre tiende a no simplemente comunicar.

Por último, queremos resaltar que en el lenguaje religioso, en sus diferentes modos de uso, el hablante, posicionado ineludiblemente como sujeto religioso, siempre está implicado en lo dicho; Tal uso de lenguaje es un juego lingüístico en el cual de forma inevitable se participa pues exige, con mayor o menor urgencia, una mínima caracterización de la relación del hablante con Dios (Conesa Ferrer y Nubiola Aguilar, 2012). Por ello, es que el lenguaje religioso no es radicalmente objetivo ni pertenece a un cierto plano puramente exterior, si no que tiende a ser la elocución y la verificación lingüística de aquello que, de algún modo, el hablante ya es, de lo que fue y de lo que eventualmente podría llegar a ser, en tanto sujeto religioso; convirtiéndose, en esto, el hablante religioso en el eje en torno al cual se despliega una dinámica de constantes reactualizaciones comprensivas del sujeto, en particular, y de la totalidad de experiencia humana, en general (Rahner, 2002).

Tal ineludible implicación del hablante en el lenguaje religioso -en nuestro caso de la pensadora veleña- nos lleva a proponer una mirada general a su biografía. Tal aproximación biográfica puede aportar comprensión sobre sus fuentes formativas, sus preocupaciones intelectuales y sus opciones lingüísticas, especialmente respecto de aquellas relacionadas con la formación y el despliegue de su pensamiento.

\section{Semblanza biográfica de María Zambrano}

María Zambrano Alarcón nació en Vélez de Málaga, en la región de Andalucía, el 22 de abril de 1904; fue hija de Blas Zambrano García de Carabante y Araceli Alarcón Delgado, ambos maestros provenientes de familias de maestros (Moreno Sanz, 1994).

En el año 1905, la familia Zambrano Alarcón se mudó a Segovia al conseguir el padre la cátedra de Gramática Castellana en la Escuela Normal de Maestros. Allí, la familia entabló amistad con el poeta Antonio Machado, con quien colaboraron en la fundación de la Universidad Popular. También ahí nace la hermana menor de la pensadora -Araceli- quien será fundamental en su vida y a quien consideraba como "la alegría más grande de su vida" (Zambrano, 1987, p. 70).

En 1913, María Zambrano comenzó el bachillerato en el Instituto de Segovia, donde solo asistía una mujer más; en esta etapa formativa la futura pensadora comienza a asimilar algunos elementos vivenciales y teóricos que resultarán fundamentales en el entramado de su pensamiento; Por ejemplo, en palabras de Ortega Muñoz (1992):

En Segovia, ciudad castellana robusta y recoleta, María se encuentra con una de las grandes pasiones de su vida, la figura y obra de San Juan de la Cruz. La lleva al mausoleo del santo su criada Gregoria y de mano de su padre descubre la poesía mística del poeta enamorado. (p. 28).

En el año 1924, la familia Zambrano Alarcón se trasladó a Madrid, donde María se matriculó como estudiante libre - debido a su mala salud- en la Facultad de Filosofía y Letras; entre 1924 y 1926 asiste, entre otras, a las clases de García Morente y Xavier Zubiri, en 
la Universidad Central de Madrid. También en este período, conoce a Ortega y Gasset quien influirá decisivamente en su formación y en su vinculación con los círculos intelectuales españoles de la época. En 1927 es invitada a la tertulia de la Revista de Occidente (Zambrano, 1987).

En Madrid, la pensadora se une al núcleo fundacional de mujeres intelectuales y artistas identificadas como "Las sin sombrero", conformadas como vanguardia feminista de la generación del 27. El nombre del grupo, al cual se incorpora, procede del gesto de Maruja Mallo y Margarita Manso quienes, con Federico García Lorca y Salvador Dalí como testigos, se quitaron el sombrero en un lugar central de la ciudad de Madrid -La Puerta del Sol-. Este gesto identitario y de transgresión pretendía romper con la norma estética imperante y, metafóricamente, proyectaba quitar cualquier obstáculo de la cabeza para liberar las ideas, la creatividad y, en general, las inquietudes femeninas (Montero Díaz, 2009).

A partir del año 1928, María Zambrano comenzó su doctorado e ingresó en la Federación Universitaria Escolar (FUE). Imparte clases de filosofía en el Instituto Escuela de Madrid, las que se vieron prontamente interrumpidas por sus problemas de salud. El diagnóstico de ese momento, y que la acompañará por el resto de su vida, fue lapidario: tuberculosis. En el reposo obligado que esta crisis de su enfermedad le impuso, escribió los primeros textos de Delirio y destino: "Adsum" y "La multiplicidad de los tiempos"; así como los primeros ensayos que serán parte de Hacia un saber sobre el alma. Comenzando a despuntar, en esos textos, su producción intelectual más significativa (Moreno Sanz, 1994; Zambrano, 1987).

En 1931 fue nombrada profesora ayudante de Xavier Zubiri, con quien llegaría a tener una gran cercanía intelectual, en la cátedra de Historia de la Filosofía en la Universidad Central, puesto que ocupó hasta el año 1935; en esa misma época inició su inconclusa tesis doctoral sobre "La salvación del individuo en Spinoza" (Moreno Sanz, 1994:38).

Su defensa intelectual de la noción de la república española la lleva a distanciarse, políticamente, de Ortega y Gasset a propósito de la valoración positiva de la monarquía española que sostenía éste; al respecto, Laureano Robles Carcedo (1991) refiere que Zambrano piensa que:

La primera exigencia ineludible en la dignificación y nacionalización española pasa por el advenimiento del régimen republicano; y nadie hay tan ingenuo y poco exigente que lo espere todo de él; pero la monarquía consumió y sacrificó a su sostenimiento todo lo que podía haber sido savia, vida de la nación, y además, la primera de las instituciones desnacionalizadas, aquí y en todas partes, pues la realeza se añade a la nación, no emerge de ella, y donde ésta es soberana queda cesante sin función, ni misión (p. 235).

Por otra parte, en la esfera filosófica, en el N138 de diciembre de 1934 de la Revista de Occidente -medio que desde sus orígenes y hasta el presente está vinculado con la difusión del pensamiento masón en occidente- la autora publica dos ensayos que incuban el germen de lo que será su pensamiento maduro, a saber: "Porqué se escribe" y "Hacia un saber del alma"; Textos que, en su contenido, reflejan su comprensión de lecturas filosóficas 
variadas, que abarcan desde Ortega y Gasset hasta Spinoza, Leibniz, Bergson, Nietzsche y Scheller. Según Moreno Sanz, a partir de este tiempo:

Zambrano hará su propuesta de llevar la razón a la oscuridad del sentir, para darle forma y figura. El segundo artículo produce en Ortega cierta perplejidad. Llamó a Zambrano a su despacho, y muy en serio, parece ser, le dijo: 'No ha llegado usted aquí (se entiende, a él) y ya se quiere ir lejos'. Aquél fue el corte del cordón umbilical filosófico. (Moreno Sanz, 1994, p. 611)

Ya en 1934, la autora ofrece una serie de tres conferencias en Gijón, en las cuales se manifiestan claramente las nociones fundamentales de su pensamiento (Robles Carcedo, 1991). Al mismo tiempo, ésta es una fase de consolidación de sus lecturas formativas; en literatura lee a Proust, Dostoyevsky y Kafka; En filosofía griega: Platón, los pitagóricos, los órficos, Plotino, los gnósticos, Séneca y los estoicos; entre los místicos: san Juan de la Cruz, santa Teresa de Ávila y san Agustín de Hipona; en filosofía moderna y contemporánea: Spinoza, Descartes, Kant, Husserl, Bergson, Heidegger, Zubiri y Jung -éste último al conocerla, incluso, le ofreció incorporarse a su equipo de trabajo- (Ortega Muñoz, 1992, pp. 13-23; Zambrano, 1987).

En un sentido formativo más amplio, su grupo de amistades incluye, entre otros y otras, a Jorge Guillén, Pedro Salinas, José Bergamín, Camilo José Cela, Luis Cernuda, Maruja Mallo y Miguel Hernández, quien por ejemplo, a modo de evidencia de tal amistad, le dedica el poema "La morada amarilla" (Hernández, 1984, p. 168; Zambrano, 1987, pp. 85-86).

Esa relación de amistad con el poeta de Orihuela puede ser significativa para apuntar como va conformándose en el pensamiento de Zambrano el perfil de la razón poética: ella se refiere a Hernández como el "Poeta-pastor" (Zambrano, 1984, p. 165) -así, con mayúscula-, vocativo que no hay que entender en relación al arquetipo del "poetapastor" tan propio de la lírica pastoril (Asensi Pérez, 1998) sino que es posible comprenderlo en relación de paráfrasis con la expresión de Heidegger (2001): "el hombre es el pastor del ser" (p. 271), con la cual el filósofo alemán señala su convencimiento de que es el hombre quien tiene la capacidad de volver a los seres a su sentido originario. Tal capacidad es, para la pensadora veleña, la particularidad del oficio del poeta y es justamente esa posibilidad de "pastoreo ontológico" la que se le hace patente en la "presencia tan inédita" de Miguel Hernández (Zambrano, 1984, p. 165) en sus idas y venidas entre Orihuela (donde oficia de pastor) y Madrid, donde pretende oficiar de poeta (cf. Ferris, 2009, pp. 109-172); podemos parafrasear diciendo que, para ella, el oficio de la poesía es el llamado a ser el pastor del ser y -cabe la imagen- que la razón poética sea el cayado en la tarea de volver a los seres a su sentido originario. Específicamente respecto a Hernández, Zambrano (1984) puntualiza que:

Era el equivalente español del indio mexicano, peruano o chileno, el sufridor de siglos contados y de los que no se cuentan (...) Seres polvorientos, de polvo de la tierra y de polvo estelar que ellos no quieren quitarse de encima, hermanos de la tierra y del sol. Seres que al extinguirse se encienden. Por sí misma, la presencia de César Vallejo se acerca a la de Miguel (p.166).

Al menos, una parte de la cercanía entre el poeta y la pensadora podemos atribuirla a la importancia que ambos daban a la palabra. Una palabra que en ambos comienza 
adquirir tonos místicos: en la pensadora desde sus fuentes formativas de Segovia y en el poeta desde el deslumbramiento frente al ambiente religioso de su Orihuela natal (Ferris, 2009, p. 51y ss.); para ella, Hernández es:

Un creyente en la comunión que se da también por la palabra. Parecía usarla por primera vez o como si la hubiera recobrado. Su poesía delata una especie de deslumbramiento ante la palabra que en él, heredero de tantos silencios, se abría. Debió de ser para él una maravilla, una pura maravilla el descubrimiento de los clásicos españoles de la llamada época barroca. (Zambrano, 1984, p. 185)

Ya en 1936, María Zambrano se sumó al manifiesto que fundó la Alianza de Intelectuales para la Defensa de la Cultura (AIDC), un importante referente de la intelectualidad republicana, colaborando en redacción de su manifiesto. Marcando el compromiso de "la libertad del intelectual" con el "pueblo puesto en pie" con una "razón armada" (Zambrano, 1998). En este gesto político la acompañan, entre otros y otras, su propio padre y Antonio Machado.

El 14 de septiembre de 1936, la pensadora contrajo matrimonio con el historiador Alfonso Rodríguez Aldave, recién nombrado secretario de la Embajada de España en Chile, hacia donde los recién casados viajaron en el mes de octubre. En su breve estadía en Santiago, publicaron la primera edición de su texto Los intelectuales en el drama de España y una pequeña antología poética de Federico García Lorca, en la Editorial Panorama de Santiago de Chile (Moreno Sanz, 1994; Zambrano, 1987). Ocho meses después, ya en plena definición favorable de la guerra civil española hacia el bando franquista, el matrimonio regresa a España. Al ser consultada de por qué vuelven si la guerra está perdida, señalará:

- Cuando fue llamada a filas la quinta de mi compañero, decidimos regresar a España, en el momento en que era más evidente que nunca la derrota de la causa en la que creíamos

- ¿Y por qué vuelven ustedes a España, si saben muy bien que su causa está perdida?

- Pues por eso, por eso mismo (Zambrano, 2016, pp. 10-11).

Al volver a España, su marido se incorpora al ejército y ella colabora en la redacción de los medios republicanos La hora de España y Madrid. Participó y también colaboró en el II Congreso Internacional de Escritores para la Defensa de la Cultura -celebrado en julio de 1937, en Valencia- donde interactuó con personalidades como Octavio Paz, Elena Garro, Nicolás Guillén, Alejo Carpentier y Simone Weil, característicamente vestida de miliciana (Zambrano, 1987).

Al inicio de 1938, Zambrano se trasladó a Barcelona, siguiendo el movimiento del gobierno Republicano que se reubicó a esa ciudad. Establecida como académica en la Universidad de Barcelona, durante el periodo de otoño, dicta un curso en el que propone el debate entre el estoicismo y el cristianismo; en cuyo contexto, a partir de la noción del "logos pitagórico", comienza a proponer una razón "mediadora" entre la razón discursiva y el pensar poético, ello desde las posibilidades dadas por nociones propias de la filosofía contemporánea (Zambrano, 1987). En palabras de Moreno Sanz (1994): 
Es singular la síntesis que Zambrano está realizando ahora entre lo que ella llama "la religión de la luz" de algunos pensadores griegos, del gnosticismo cristiano, de Plotino, y el racionalismo de Espinoza, Leibniz y algunos románticos alemanes. $Y$ (...) la confrontación que está haciendo de Heidegger a través, precisamente, de dos hitos españoles, Unamuno y Machado. (p. 613).

El 25 de enero de 1939, capitula Barcelona: se acerca el fin de la guerra civil y comienza el exilio republicano (Beevor, 2005). Tres días después, María Zambrano cruzó la frontera hacia Francia en compañía de su madre, su hermana Araceli y el marido de ésta. Tras un breve tiempo en Francia, la pensadora se reúne con su marido y parten hacia México invitados por la Casa de España, permaneciendo antes un tiempo en Nueva York y La Habana, donde fue invitada como profesora de la Universidad y del Instituto de Altos Estudios e Investigaciones Científicas (Zambrano, 1987). De Cuba pasó a México, donde publicó, entre otros, sus libros Filosofía y poesía y Pensamiento y poesía en la vida española (Moreno Sanz, 1994).

Entre 1940 y 1945, trabajó con intensidad en seminarios y conferencias, dictando lecciones y cursos en diversas instituciones cubanas y puertorriqueñas: El Departamento de Estudios Hispánicos de la Universidad de Puerto Rico, la Asociación de Mujeres Graduadas y el Ateneo de La Habana. (Zambrano, 1987). Paralelamente continuó publicando artículos y libros tales como: La Confesión: género literario y método, La agonía de Europa y El pensamiento vivo de Séneca (Moreno Sanz, 1994). Una vez finalizada la II guerra mundial, viaja a París con motivo del fallecimiento de su madre. Allí encuentra a su hermana Araceli desecha por las torturas, el encarcelamiento, extradición y fusilamiento de su marido. María Zambrano no se separará de ella hasta su muerte. La pensadora vivirá en París hasta 1948 (Zambrano, 1987).

Separada de su esposo, en 1948, María y su hermana se trasladaron a La Habana y de allí nuevamente a México. En esta estancia mexicana, Zambrano afianza su amistad con Gabriela Mistral, quien en ese tiempo oficia de Cónsul de Chile en Veracruz y a quien ya conocía desde el congreso de la Federación Universitaria Escolar (FUE) celebrado en Madrid en 1928, al cual la poeta chilena asistió en representación de Chile y Ecuador (Zambrano, 1987; Quezada, 2010). La pensadora y la poeta mantuvieron su contacto por correspondencia, por lo menos, hasta la siguiente década (Zambrano, 1952).

En 1950, las hermanas Zambrano se trasladan nuevamente a La Habana, pero la situación económica las obliga a volver a Europa: su condición de mujeres errantes se vuelve un sino; Entre 1950 y 1953, las hermanas realizan constantes traslados entre Europa y América; nomadismo que se detuvo con la permanencia en Roma, de forma relativamente estable, entre 1953 y 1963 (Zambrano, 1987). A este período romano pertenece un amplio corpus de artículos, ensayos y libros, entre los cuales destacan España, sueño y verdad, El hombre y lo divino, El sueño creador y La España de Galdós (Moreno Sanz, 1994).

Las hermanas Zambrano nuevamente puestas en movimiento, se instalan en una casa llamada "La Pièce", en una zona boscosa del departamento francés de Jura (Zambrano, 1987). Ahí la pensadora produjo, entre otras, sus obras La tumba de Antígona, El hombre y lo divino y Claros del bosque. En esta fase, su obra comenzó a valorarse en España a partir de la 
publicación en la Revista de Occidente, en febrero de 1966, del artículo de José Luis López Aranguren Los sueños de María Zambrano, al que siguieron los trabajos de José Ángel Valente. Por otra parte, Araceli Zambrano muere el 20 de febrero de 1972, lo que significó un fuerte golpe para la pensadora española (Moreno Sanz, 1994).

Ya en 1981, la pensadora fue condecorada con el Premio Príncipe de Asturias de Comunicación y Humanidades, en su primera edición. También, el ayuntamiento de VélezMálaga -su ciudad natal- la nombró Hija Predilecta. Al año siguiente, la Junta de Gobierno de la Universidad de Málaga acordó otorgarle el grado de Doctora honoris causa.

El 20 de noviembre de 1984, Zambrano regresó a España tras casi medio siglo de viajes y exilio. Se instaló en Madrid, donde continuó tanto su actividad intelectual como los reconocimientos: fue nombrada Hija Predilecta de Andalucía en 1985; en 1987 se organizó la fundación que lleva su nombre. Mientras que en 1988, se le concedió el Premio Cervantes, otorgado por primera vez por la Asociación de Academias de la Lengua Española (Moreno Sanz, 1994).

Finalmente, María Zambrano Alarcón murió en Madrid el día 6 de febrero de 1991; fue enterrada entre un naranjo y un limonero en el cementerio de Vélez-Málaga. Poco tiempo después, a esa tumba fueron trasladadas quienes ella llamaba sus "dos Aracelis", es decir, los restos mortales de su madre y su hermana (Moreno Sanz, 1994). En la lápida de las mujeres puede leerse, a modo de epitafio, un verso del Cantar de los Cantares: "Levántate amiga mía y ven" (cf. Ct. 2,10b).

\section{Aproximación al pensamiento teologal de María Zambrano}

\subsection{Pensamiento y canon}

Hay factores que hacen de la pensadora española, más allá de su singular biografía, una representante atípica de la filosofía contemporánea. Tal particularidad se sustenta, por una parte, en la singularidad del conjunto de su obra y, por otra parte, en el modo en que despliega su pensamiento a través de un lenguaje muy personal: a veces enigmático y equívoco, aunque siempre inspirador (Laguna García, 2015). Son esas notas atípicas algunas de las razones que sustentaron el llegar a cuestionar el talante filosófico del conjunto de su pensamiento, polémica que también podría ayudar a explicar el tardío reconocimiento de la autora y su relativamente tardía incorporación al "canon" filosófico contemporáneo (Bundgård, 2009).

También, la identificación de la tradición filosófica occidental con la razón lógicodiscursiva, con la preeminencia de la arquitectura sistemática del pensar y con la lógica instrumental son asimilaciones que, al decir de Zambrano, tienden a negar la pluralidad de la realidad pensada. Negaciones consecutivas que, por otra parte, excluirían del ámbito de lo estrictamente filosófico no solamente la obra de María Zambrano sino también la de otras y otros autores de los cuales no se duda ya de su pertenencia al canon filosófico (Laguna García, 2015). 
Además, otro factor que puede incidir en la marginalidad de la autora, respecto del canon filosófico, es su condición de mujer. Tal tradicional marginación, basada en la condición de género, es un fenómeno general en la historia de la filosofía occidental. Tal distorsión en la recepción y validación del pensamiento ejercido por mujeres está siendo cada vez más evidenciado y tiende a ser parcialmente superado (Amara y Zappi, 2018).

En ello, a modo general, entendemos que la polémica relativa al talante filosófico de la obra de Zambrano ineludiblemente involucra la noción previa que se tenga de eso que Ilamamos filosofía (cf. Zea Aguilar, 1987; Zubiri, 2004; Romero González, 2017). Esa última noción es un tópico central en el pensamiento teologal de María Zambrano pues crítica constantemente a la tradición filosófica occidental por haberse auto desplegado a partir de una idea muy restringida de lo que es filosofía; olvidando, en ello, que una buena parte del problema filosófico, en el horizonte de tradición europea, ha de ser la propia filosofía, dado que ella en su despliegue disciplinar no suele comenzar con una definición de objeto y campo, es decir, explicitando los límites de lo que ella misma es; tal y como tiende a ocurrir con el resto de las disciplinas.

La filosofía, para Zambrano, ha de partir en la experiencia del radical encuentro de admiración que suscita lo real; una experiencia con pretensiones de totalidad, que es sostenida a posteriori justamente a partir del sentido de las posibilidades de la interrogación posterior (Zambrano, 2016, pp. 15-19). Toda demanda y posibilidad de sistematización es posterior y secundaria. En palabras de la pensadora:

Si el pensamiento nació de la admiración solamente, según nos dicen los textos venerables, no se explica con facilidad que fuera tan prontamente a plasmarse en forma de filosofía sistemática; ni tampoco que haya sido una de sus mejores virtudes la de la abstracción, esa idealidad conseguida en la mirada, sí, más que un género de mirada ha dejado de ver las cosas. Porque la admiración que nos produce la generosa existencia de la vida en torno nuestro, no permite tan rápido desprendimiento de las múltiples maravillas que la suscitan. $Y$ al igual que la vida, esta admiración es infinita, insaciable y no quiere decretar su propia muerte. (Zambrano, 2016, p. 17)

Salvando las evidentes diferencias formales, estas nociones de la pensadora coinciden, en trazos gruesos, con las de algunos de sus contemporáneos más insignes. Lo cual tiende a situar su pensamiento en una cierta centralidad temática en el ámbito filosófico contemporáneo (cf. Heidegger, 1997, pp. 25-37; Zubiri, 2004, pp. 154-155).

\subsection{Pensamiento teologal de María Zambrano}

En una primera aproximación, diremos que el pensamiento teologal de María Zambrano aborda el fenómeno religioso desde una heurística basada en la noción de la apertura a la trascendencia en tanto experiencia vital. A partir de tal noción, la pensadora vislumbra la posibilidad de superar, por vía de un cierto desborde trascendental, los márgenes limitantes que caracterizan la comprensión de la existencia humana. Desborde que solo podría desplegarse si se verifica una cierta condición de apertura que, a su vez, define la trascendencia como experiencia vital (Pulgar Castro, 2015). A propósito de tal idea de apertura la pensadora afirma que: 
El que sueña pide salir de ese estado en que, desgraciado o feliz, yace como larva en su capullo. De ese estado de inmanencia, que no parecer ser propio de la vida humana. Pues si la idea inmanentista acerca del hombre correspondiese a la realidad, la vida sería como los sueños; la realidad, la circundante y la propia, sería solamente padecida, comentada como lo es en sueños, anotada, deformada, entrevista. Y aún las acciones con ella y aun sobre ella tendrían la misma condición: serían igualmente padecimiento, pasividad. (Zambrano, 2004, p.16)

Así, la apertura a la trascendencia es concebida por Zambrano como un descentramiento, en la medida que es descrita como una forma -poseída como posibilidad en el si-mismo de la humanidad- de darse la capacidad de salir de tal en-sí-mismo. Tal desplazamiento tendería a orientar la forma de aprehender la experiencia religiosa, especialmente si se procura comprender las implicancias antropológicas religadas a la vinculación posiblemente dada entre la humanidad y Dios, concebido éste como aquel que está más allá del si-mismo humano (Balza Múgica, 2000; Rahner, 2002).

También, la apertura a la trascendencia es concebida por Zambrano como el campo de verificación del grado de veracidad que la experiencia religiosa otorga a la existencia humana. En ese campo, de talante axiológico, destaca la posibilidad de validación del diálogo entre Dios y la humanidad. Diálogo que, a su vez, tiene como elemento dinamizador a una especie de apertura individual, en la cual un sujeto particular puede llegar a auto reconocerse, en la intimidad de su conciencia, como sujeto creyente. En otras palabras, la experiencia de apertura despliega como posibilidad el hecho de que un sujeto individual se auto reconozca favorable a aceptar como elemento fundante de su existencia a una realidad, radicalmente otra, que lo sobrepasa y que lo desborda pero en la cual encuentra su sentido último (Zambrano, 2004). Así, en la apertura a la trascendencia, tal y como la comprende María Zambrano, la disposición de apertura a lo Otro se fusiona la idea de trascendencia, entendida como superación de los propios límites, tanto a nivel individual como genérico (Rahner, 2002). En ese sentido es que Zambrano afirma la disposición de apertura a la trascendencia como el elemento modal constitutivo del ser persona humana. Apertura es, para la pensadora, la vía por antonomasia de humanización (Zambrano, 1991).

La pensadora veleña, en este punto de su pensamiento teologal, integra circunstancias culturales cuando señala la posibilidad de un desarrollo de humanización distorsionado, debido a que cierta parte de la reflexión contemporánea -originalmente destinada a comprender la relación de la humanidad y Dios- ha tendido a ser, más bien, una arquitectura sistémica, que estaría sostenida por fuertes soportes racionales; tal conjunto de construcciones, en una desnaturalización de las mismas, devienen en ser limitantes para asumir la disponibilidad a lo trascendente y, por tanto, dificultan la apertura; Con lo que se enlentece o se detiene del todo el mayor factor activo en el proceso de lograr una genuina humanización y una aproximación comprensiva hacia lo divino (Zambrano, 2004).

Tal indicación de Zambrano sobre el rol particular de la razón, se enmarca en su descripción y su crítica general de la racionalidad moderna. Al respecto, en su texto Los bienaventurados señala que: 
La filosofía moderna, origen de la física matemática, se queda en soledad para dar una imagen del cosmos, y al desprenderse por completo de la revelación queda librada a sí misma, como quería. Y el hombre que a la filosofía o a la ciencia se acoge, aun el hombre común que respira este clima, queda librado a su soledad humana, a la soledad del género humano sin cosmos y sin revelación. $Y$ aquellos que vivían dentro aún de una religión determinada quedan escindidos, separados del pensamiento filosófico-científico y del ambiente intelectual y moral que de ellos emana, creyendo a medias y por partida doble. (Zambrano, 1991, p. 12)

Junto con la crítica a la limitación que la razón puramente discursiva puede llegar a representar en el logro de una comprensión de lo religioso, Zambrano plantea su postura crítica respecto del proyecto totalizante de la modernidad (entendido, en este contexto particular, como el despliegue de la razón secular). En su pensar, tal proyecto se levanta como un obstáculo sistémico para asumir la actitud de apertura a la trascendencia. En ello, percibe que la razón moderna tiende a representar la opacidad de la experiencia de autoconciencia que, una vez extendida en el ámbito interior del sujeto creyente, puede llegar a verse envuelta en una serie de mutaciones y palimpsestos de posibles perspectivas interpretativas relativas a su propia situación, en tanto creyente. Para Zambrano, la razón moderna dificulta la conciliación de lo humano por lo humano (Zambrano, 1991).

Tal condición de constante readecuación de lo humano va acompañada de una especie de readecuación vicaria de lo divino, en tanto ambas realidades se relacionan en la esfera del sujeto creyente. En la aprehensión de tal proximidad vicaria, por una parte, hay que cuidar y mantener el criterio de que lo divino sea percibido per se como "lo irreductible a lo humano" (Zambrano, 2007, p. 136) y, por otra parte, también es necesario señalar que aquello Otro, que es captado en virtud de la actitud de apertura y que es conceptualizado como independiente de la realidad humana, es tensado y soporta, al menos en el nivel perceptivo, del cambio por readecuación pues es afectado en la aprehensión de su perfil por las formas que la experiencia religiosa le confiere. Tal contingencia de lo divino, al menos en el nivel de la aprehensión, lleva a la pensadora a afirmar que:

En la historia conocida siempre ha llegado un momento en que los dioses han muerto. $Y$ es extraño. Lo divino, aquello que el hombre ha sentido como irreductible a su vida, sufre eclipses (...) Y en cualquiera de los casos ha llegado el instante terrible de que 'eso divino' irreductible a lo humano ha corrido la suerte de lo humano: pasar, ser vencido y aún morir. (Zambrano, 200, p.136)

A partir de tales tensiones y readecuaciones, María Zambrano propone una aproximación a la comprensión del ser humano; su pensamiento se despliega, en este punto, como una propuesta antropológica teologal que pretende abordar los aspectos más importantes que, según su visión, configuran lo humano (Lizaola Monterrubio, 2008; Laguna García, 2015).

En primer lugar, según la autora, para entender el vivir humano es necesario abordar la relación entre "lo divino" y "lo sagrado", ya que la aparición de los dioses en la vida humana implica una conexión performativa y necesaria con la realidad primera, es decir, con lo sagrado (Lizaola Monterrubio, 2008). En ello, el perfilamiento de los dioses va a constituir, para la pensadora, la primera relación con la realidad y el origen de las primeras preguntas, a 
partir de las cuales se dispone el despliegue del ser humano en tanto tal. Tales interrogantes no son aún de carácter filosófico, si no que se articulan, en este punto, como una especie de "pre ontología" o, si se quiere, como una "ontología menor" (Romero González, 2017). Pero ya son, en ese estadio inicial, la razón de posibilidad ineludible sin las cuales la filosofía no se hubiera desarrollado.

Tal primera relación del ser humano con la realidad no tiene, para Zambrano, un carácter predominantemente racional. Por el contrario, en un primer momento el ser humano se relaciona con la mundaneidad (Heidegger, 1997, pp. 94-98) a través del delirio, que ya en sí mismo constituye un cierto saber experiencial. Desde esa experiencia de delirio original -que es concebida como parcial, aunque con pretensión de totalidad- es desde donde se produce el tránsito de lo sagrado hacia lo divino. Del delirio ante lo sagrado surgen los dioses, afirma repetidamente Zambrano (Zambrano, 2003).

Ese delirio del principio, en su naturaleza original y originante, se resiste a ser englobado por la razón. El pensamiento teologal de María Zambrano puede ser entendido, en esto, como un proyecto intelectual que se esfuerza por aproximarse, por esclarecer y por aprehender aquel delirio primigenio que tiende a permanecer oculto, a pesar de ser la base de nuestro ser. Tal delirio parece gozar de la sombra y hacia esa oscuridad es donde se dirige, en tanto "pro-yecto", el pensamiento de María Zambrano (Zambrano, 2011a).

Como se señaló anteriormente, en los inicios de su proyecto intelectual la autora contó con la influencia formativa de José Ortega y Gasset. Ella reconoce en su maestro a un pensador que desarrolló una filosofía básicamente analítica y que se esforzó por estar libre de supuestos, en el afán de desplegar el proyecto fenomenológico propuesto por Husserl (Zambrano, 2011b). De la misma manera, en tanto parte de una generación que apunta en esa dirección, valora positivamente el rol de Ortega en la introducción del pensamiento fenomenológico en una España marcada a fuego por la neoescolástica (Ferris, 2009, pp. 2128; Zambrano, 2011b; Zubiri, 1999). Sin embargo, no acepta la orientación marcadamente "vitalista" de Ortega y Gasset, es decir, no acepta que la vida sea el eje central de la filosofía. Ella postula que lo que lleva a interrogar es el delirio del contacto primero con la realidad. La realidad misma, para Zambrano, tiene preeminencia respecto a la vida: ésta es quien se apoya en la primera y no a la inversa (Zambrano, 2011a).

En su proyecto de llegar a la aprensión del deliro primero, no le es suficientemente primera la "razón vital" de Ortega y Gasset (Zambrano, 2015) y le es necesaria un tipo de racionalidad que sea capaz de llegar donde no llega la razón discursivo vitalista. Le es necesario un nuevo tipo de razón que prefigura en su texto Hacia un saber sobre el alma:

Era necesario topar con esta nueva revelación de la Razón a cuya aurora asistimos como Razón de toda la vida del hombre. Dentro de ella vislumbramos que sí va a ser posible este saber tan hondamente necesitado. El cauce que esta verdad abre a la vida va a permitir y hasta a requerir que el fluir de la «psique« corra por él. Tal es nuestra esperanza. (Zambrano, 2008, p. 30)

La propuesta y justificación de tal nuevo tipo de razón es, probablemente, el mayor aporte de la pensadora a la reflexión contemporánea. Esta es una valoración de la que 
participan Maillard, Bungard, Ortega Muñoz y Jesús Moreno, entre otros estudiosos del pensamiento de María Zambrano (Pulgar Castro, 2015) y a la cual suscribimos plenamente. A continuación, se revisará ese nuevo tipo de razón propuesto por la autora.

\section{Razón poética, revelación y saber}

En sus textos Los intelectuales en el drama de España y Pensamiento y poesía en la vida española, ambos publicados en 1936 (Moreno Sanz, 1994), María Zambrano propone al "conocimiento poético", desplegado a partir del "método de la razón poética" (Zambrano, 1998), como un modo de entendimiento capaz de captar la realidad primera, a partir de una potencia de aprehensión que sobrepasaría, por mucho, las posibilidades comprensivas de la racionalidad de carácter puramente cartesiano.

En ello, concede al saber poético un protagonismo que, según la pensadora, le había sido negado. Le confiere a la poesía una importancia central como una posibilidad privilegiada de aprehensión creativa, etimológicamente alineada con la "poiesis" griega, entendida como una actividad creativa que es capaz de otorgar existencia a algo (Asensi Pérez, 1998). En particular, Zambrano propone a la racionalidad poética, en general, como la senda privilegiada para dar con la comprensión de lo humano y de lo divino. Con lo cual la pensadora española se inscribe en una cierta tradición (que va desde Novalis y Schlegel hasta Nietszche y Heidegger) que concibe a la poesía como un "saber extático, es decir, que revela verdades trascendentes, inaccesibles a las actividades cognitivas profanas" (Schaeffer, 2012, p. 15).

La propuesta de la autora se basa, en última instancia, en una distinción griega respecto a dos modos del conocimiento: el nous y la dianoia. El nous concebido como el conocimiento más profundo y directo, como una especie de visión interior que da acceso a verdades profundas, en virtud de ser un saber intuitivo, conectado con la vida concreta. La dianoia, por otra parte, entendida como una razón "segunda", que en una operación posterior, a partir de certezas alcanzadas por el nous, extrae consecuencias específicas, que van conformando un cierto inventario de conocimientos objetivos (Asensi Pérez, 1998; Zambrano, 1998).

También, esa distinción se puede percibir, a trazo grueso, en la propuesta de Xavier Zubiri, contemporáneo y formador de la pensadora veleña, cuando éste postula a la "inteligencia sentiente", conceptualizada como potencia unitiva de lo intelectivo y lo sensorial, como la facultad humana que es capaz de realizar la aprehensión primordial de la realidad. Y aunque, según el pensador vasco, el sentir y el entender no pueden identificarse, tampoco pueden separarse totalmente, porque el sentir y la intelección constituirían dos tiempos de un solo acto de aprehensión. Según Zubiri, solo desde el despliegue de la inteligencia sentiente aprehendemos lo real como real de suyo. Las cuestiones posteriores relativas a qué es la realidad y qué son las cosas concretas, serán campos subsiguientes de reactualizaciones, mayoritariamente propias del logos y la razón. (Zubiri, 2003; Correa Schnake, 2012, pp. 43-77). 


\subsection{Poesía y revelación}

Para la pensadora veleña, en tal actividad intuitiva de aprehensión poética, desplegada por la vía del nous, se logra ciertamente una revelación profunda de lo que la realidad es. En esa revelación, la verdad del ser no surgiría inicialmente a través del asombro o la pregunta, tal y como lo sostiene la tradición filosófica occidental (Heidegger, 1997; Bundgaird, 2009), si no que emerge como revelación que enmudece, que suscita silencio, que lleva a callar. Al respecto, Zambrano señala que: "La pregunta qué es el ser la he abolido de la filosofía hace tiempo. En vez de preguntar, creo en la revelación de la filosofía y al que revela, no se le pregunta. Solo cabe callar" (Zambrano, 2009, p. 280).

Tal revelación primaria -en su naturaleza "silenciosa", original y originante- es la manifestación de la que se deriva toda posibilidad de desplegar una hermenéutica de lo sagrado, en la medida en que tal revelación se manifiesta como una intuición integradora de todos los aspectos de la realidad. Realidad que para Zambrano está "colmada de dioses" (Zambrano, 2007), en una situación de saturación que no es otra cosa que aquello que llamamos "lo sagrado" (Elíade, 1983).

Para María Zambrano, hay un largo proceso proto histórico que va desde lo sagrado, entendido como el espacio donde primariamente la humanidad se encuentra sumergida, hasta la articulación de la pregunta de la filosofía por el Ser (Heidegger, 1997, pp. 25-63). Para la pensadora veleña, con la articulación de la pregunta por el Ser surge el hallazgo de la conciencia y comienza la soledad de la humanidad. Respecto a lo sagrado y al inicio de la filosofía, Zambrano (2007) puntualiza que:

El origen de la filosofía se hunde en esa lucha que tiene lugar dentro todavía de lo sagrado y frente a ello. La filosofía nació, fue el producto de una actitud original, habida en una rara coyuntura entre el hombre y lo sagrado. La formación de los dioses, su revelación por la poesía, fue indispensable, porque fue ella, la poesía quien primeramente se enfrentó con ese mundo oculto de lo sagrado (p. 76).

Para la pensadora, a partir de la articulación de la pregunta por el Ser, la tradición filosófica occidental impuso un solo tipo de razón discursiva, centrada en un logos único y hegemónico, que se amplía forzadamente hasta la desnaturalización de sí mismo. Con lo que queda en la penumbra de lo "no revelado" algo fundamental: la realidad primordial en su ocurrir heterogéneo, multiforme y poli lógico.

Para afrontar tal imposición paradigmática establecida por y desde la tradición, según la pensadora veleña, urge liberar la palabra poética del estado subalterno en que la sitúa la coerción de la racionalidad puramente lógica. Urge recobrar la palabra poéticamente translúcida, liberada de rasgos conceptuales. En definitiva, urge restablecer la palabra en tanto posibilidad de revelación (Zambrano, 2007).

Según Zambrano, para tal restablecimiento es indispensable "in-vocar", en una suerte de voceo interior con rasgos vocacionales, a la palabra poética para acceder a la eventual aprehensión del misterio del Ser, mismo que tiende a ocultarse a la palabra de naturaleza racionalista. La palabra reveladora, devenida en poesía, tiende a decir con mayor capacidad de elocución aquello que no puede expresar o que solo alcanza a balbucear la 
palabra eminentemente lógica, devenida en palabra "bárbara". Pensamiento, poesía y revelación aparecen así entrelazados en un único caudal comprensivo. Desde ese sentido, Zambrano afirma que la verdad -y privilegiadamente, la verdad de lo humano- surge por revelación poética, en un "correr el velo" que comporta, como elemento constitutivo, una actitud lírica (Zambrano, 2016).

En relación a esas nociones y sus posibles relaciones, se puede observar en la redacción de sus textos que la pensadora veleña se va desinteresando paulatinamente de los aspectos histórico-sociales involucrados, en una "dirección", en cierto sentido, distinta a la tomada por otros pensadores que rondaron esas mismas nociones y relaciones (cf. Elíade, 2000; Otto, 2001). Ella comienza a proponer, en cambio, una especie de "mística" de la comprensión radical, directamente relacionada con la obra y la figura de San Juan de la Cruz (Laguna García, 2015), ello en una línea muy propia de la generación del 98, es decir, en el reconocimiento de lo hispánico en tanto temática y pista heurística (Asensi Pérez, 1998). Así, el pensamiento poético-religioso de Zambrano también pretende alcanzar lo primariamente indeterminado a través de la experiencia mística del amor.

La poesía mística de San Juan de la Cruz representa para María Zambrano un modelo de un ejercicio místico-poético, que comporta el desarrollo de una comprensión y significación religiosa global, desde la singularidad que implica la ausencia del amado:

...El motivo ausencia en el amor, es un motivo claramente platónico que a los historiadores de la literatura les compete estudiar. 'Ausencia' en el amor, porque la presencia jamás es posible y si alguna vez se diera, ya no se cantaría.

Así, El Cántico Espiritual del místico San Juan de la Cruz, es el canto a la ausencia del amado. Aquí explicable porque su amado, en efecto, no es visible. Pero, en la poesía profana de este tiempo y del anterior se vería también constantemente este motivo de ausencia y de búsqueda constante de las huellas del amado. La naturaleza entera se transforma: ríos, árboles, prados. La luz misma conserva la huella de la presencia amada, siempre esquiva e inalcanzable. (Zambrano, 2016, p. 64)

San Juan de la Cruz introduce en el pensamiento zambraniano una clave hermenéutica: la posibilidad de una tenue revelación de presencia de Lo Absoluto que aún, a pesar de su sutileza, es capaz de conferir solidez metafísico-religiosa al devenir de la existencia humana. Tal manifestación fundante no queda reducida a la esfera de la existencia humana sino que tiende a envolver a toda la realidad (Zambrano, 2016, pp. 4566). En este punto, para Ana Bundgård, la figura del santo es clave en el concepto de la noción de la razón poética como vía de acceso a la revelación del sentido de lo Absoluto:

Bajo la presencia de san Juan de la Cruz, construye la autora desde la época mexicana una razón poética que vuelve siempre a los orígenes, al sentir originario del ser. De esta forma, oscilando dialécticamente entre el no ser y el ser, la razón traspasa los límites del entendimiento e intuye, en un 'claro' de la conciencia, la presencia de lo absoluto. (Bundgård, 2005, p. 131)

Hay que señalar que, en el conjunto de su propuesta de comprensión poética, la pensadora española no menosprecia la razón respecto de la poesía, si no que pretende 
situarla en el marco justo de las potencialidades que le son propias. En su texto Filosofía y poesía, Zambrano (2016, pp. 15-26) lleva a cabo una revisión de las relaciones que en la historia se han dado entre estas dos posibilidades de comprender. A partir de tal revisión, ella plantea que para conocer cabalmente la realidad, ambas son necesarias:

No se encuentra el hombre entero en la filosofía; no se encuentra la totalidad de lo humano en la poesía. En la poesía encontramos directamente al hombre concreto, individual. En la filosofía al hombre en su historia universal, en su querer ser. La poesía es encuentro, don, hallazgo por gracia. La filosofía busca, requerimiento guiado por un método (Zambrano, 2016, p. 15).

Entonces, la razón poética intenta conciliar dos vías como afluentes: razón y poesía. No se trata, insistimos, de excluir de la razón o de desnaturalizarla respecto de sí misma, para privilegiar otras posibilidades de aprehensión. En palabras de Zambrano (2004):

Así pues, el conocimiento que aquí se invoca, por el que se suspira, este conocimiento postula, pide que la razón se haga poética sin dejar de ser razón, que acoja al «sentir originario" sin coacción, libre casi naturalmente, como una physis devuelta a su original condición (p. 56).

La autora propone, a partir de tal apreciación dual, valerse tanto de la filosofía como de la poesía. En ello se basa fundamentalmente su método de acercamiento a la verdad pero también, con la misma base, crítica a la tradición occidental por haberse inclinado hacia el uso exclusivo y excluyente de uno de los dos lenguajes como lenguaje de la verdad. La pensadora afirma que tal exclusión de la poética, respecto del campo de la verdad, comienza a partir de la aparente condenación de la poesía que Platón lleva a cabo en "La República" en los libros II, III y, sobre todo, en el libro X (Platón, 1986). Allí se iniciaría la marginación que se mantendrá y ampliará a lo largo de la historia de occidente, es decir, para ella ese es el punto de inicio de la visión reduccionista de lo filosófico, que llegará a admitir al razonamiento lógico como la vía exclusiva para alcanzar la verdad. En palabras de Zambrano:

Es en Platón donde encontramos entablada la lucha con todo su vigor, entre las dos formas de la palabra, resuelta triunfalmente para el logos del pensamiento filosófico, decidiéndose lo que pudiéramos llamar "la condenación de la poesía"; inaugurándose en el mundo de Occidente la vida azarosa y como al margen de la ley de la poesía, su caminar por estrechos senderos, su andar errabundo y a ratos extraviado, su locura creciente, su maldición(...) Aunque los filósofos no han gobernado aún ninguna república, la razón por ellos establecida ha ejercido un imperio decisivo en el conocimiento (Zambrano, 2016, pp. 15-16).

Tal constante crítica de la tradición occidental realizada por Zambrano, recuerda -reconociendo a priori todas las distancias y diferencias dadas- a la realizada incesantemente por Nietzsche, por ejemplo, en la oposición que establece éste entre cultura y civilización (Lemm, 2010, pp. 37-69). Tal semejanza la percibimos también en, al menos, otros dos aspectos: En primer lugar, en ambos percibimos una cierta atracción por la potencia creadora y reveladora del lenguaje. Sus pensamientos, aparentemente asistemáticos, tienden a escapar de los cánones establecidos en el contexto de cada cual en particular y del canon occidental, en general. En esto, la obra de ambos refleja un interés 
marcado en el estilo por sobre el método: hay mucho de aforismos nietzscheanos en la prosa de Zambrano y hay mucha razón poética en la prosa de Nietzsche (Bundgård, 2009; Lemm, 2010). En segundo lugar, el contraste que establece María Zambrano entre la palabra poética y la palabra lógica, y la preeminencia explicativa que le atribuye a la primera por sobre la segunda, tiene cierto paralelismo con la reivindicación, por parte de Nietzsche, del espíritu dionisíaco frente a la hegemonía de lo apolíneo (Bundgård, 2009; Lemm, 2010; Nietzsche, 1985). En esto, tanto Zambrano como Nietzsche proponen superar el dualismo supuestamente antagónico dado entre el lenguaje poético y el filosófico, pues para ambos tal separación no se explica en el origen mismo de la filosofía ni le es connatural sino que es posterior e impuesta (Fink, 2000; Nietzsche, 1985; Zambrano, 2016).

Más allá de ese posible paralelismo, para superar la asimetría dada en la historia entre las posibilidades explicativas del lenguaje poético y del filosófico, María Zambrano propone acoplar ambas dimensiones en la noción de "razón poética". Para ella lo poético y lo filosófico se complementan: el poeta "olvida lo que el filósofo recuerda y es la memoria misma de lo que el filósofo olvida" (Zambrano, 2016, p. 43). Poesía y filosofía, al mismo modo que memoria y olvido, son modos de la palabra que, aunque divergentes, no son irreconciliables.

María Zambrano plantea ampliar lo filosófico con el caudal de lo poético y pretende para ello restarle dureza al concepto racional para que fluya, se adapte y logre aprehender la multiplicidad de lo existente. Para que, en definitiva, se convierta en palabra con eficacia de revelación. Este planteamiento es la síntesis de la potencia reveladora de la "razón poética".

\subsection{Poesía y saber}

La pensadora veleña reconoce que la palabra de talante racional tiende a ser pensamiento filosófico, también señala que este tipo de pensamiento surge del éxtasis originario, devenido en asombro, ante las cosas que existen y que, además, el pensamiento filosófico se articula primariamente a partir de la pregunta por el ser de tales cosas. Al decir de Zambrano, conocemos el origen de este tipo de pensamiento:

Surge entonces el asombro, ese asombro que es entusiasmo encendido en la certeza de que hay un ser, un universo, un orden. Y de él se ha nutrido no sólo la pregunta filosófica que surgió con Tales de Mileto, sino todo el esplendoroso proceso de la filosofía griega, de la Filosofía. (Zambrano, 2011b, p. 140)

Desde ese primer momento, según Zambrano, estaría incubada en el pensamiento filosófico la duda relativa a si las cosas son lo que aparentan e, incluso, si tales cosas son realmente. Tal posibilidad de duda, puede involucrar hasta al propio sujeto pensante, en tanto objeto de la duda. Esta última inclusión representa para la pensadora, como acto de "re-flexión", la razón de posibilidad de la conciencia humana (Zambrano, 2011b). Sin embargo, en la tradición occidental, desde Descartes, a partir de tal duda se postula la certeza racional de las cosas y del sujeto, en tanto ser pensante. Sobre tal certeza, se ha articulado paulatinamente una construcción sistémica y rígida que vincula fuertemente al sujeto y al objeto. Tal construcción pretende poseer su justificación última en la razón. Este es un proceso en el cual, casi sin escalas, se habría pasado de la duda primaria a una cierta divinización de la razón (Bundgård, 2009; Zambrano, 2016). 
En tal proceso dado en occidente, postulamos que la idea de "razón" -logos, palabra, estudio, etc.- ha experimentado una larga historia de transposición e inclusive de transculturación: siendo de origen mítico, el concepto "razón" fue identificado por largo tiempo con un algo divino y sobrehumano del que la humanidad participa. Ello se acentúo en la cristología patrística y en el platonismo cristianizado (Otto, 2001). La "secularización" del concepto razón, recién despuntó con el nominalismo medieval y se configuró, definitivamente, con el racionalismo continental moderno. Pero a pesar de su emancipación de lo sagrado, al menos a lo largo de la modernidad cartesiana, la razón mantuvo un aura extraordinaria, casi divina. Hasta podríamos decir que en la modernidad, la razón fue "redivinizada", en tanto fue presentada como una dimensión que transciende el mundo experimental. Recién, la llamada post modernidad propone de-construir este nuevo mito, en especial, a partir de su crítica de la llamada "racionalidad instrumental" (Romero González, 2014).

Por todo ello, según María Zambrano, el pensamiento filosófico ha transfigurado equívocamente lo sagrado pues ha tomado la realidad de la naturaleza, múltiple y polisémica, y la ha amoldado en un único tipo de pensamiento. Según ella, tal actividad intelectual ha igualado el ser de la realidad con el pensar tal realidad. La autora postula que el pensamiento de talante exclusivamente filosófico, en esto, representa una limitación para aprehender aquello que no puede ser solo pensado.

A partir de lo anterior, Zambrano propone una distinción fundamental entre "saber" y "pensar": El "saber" (en algunos pasajes de su obra: "la sabiduría") es un algo dado en las diferentes culturas y que se hace presente en ellas a partir de la acumulación de experiencias, a lo largo de un margen amplio de tiempo; El "pensar", en cambio, es una labor técnica y erudita, de naturaleza enciclopédica, que despliega su comprensión en un momento concreto y determinado, y sería un algo adquirido de forma relativamente rápida por un sujeto concreto (Zambrano, 2016). Otra diferencia importante entre "saber" y "pensar", a juicio de María Zambrano, se encuentra en la dimensión metodológica de ambas nociones. En sus palabras:

El saber es experiencia ancestral o experiencia sedimentada en el curso de una vida. ¿Y cómo transmitir esta experiencia? Y si resulta problemático el transmitir y aun el adquirir la experiencia es porque se trata de experiencias vitales, es decir: de una experiencia que no es repetible a voluntad, según lo son las que se efectúan en los laboratorios. (Zambrano, 2016, p. 147)

Tal diferencia entre "saber" y "pensar", así caracterizados, lleva a deducir que para el saber no existe, en principio, un método posible, tal y como si es posible concebirlo en el ámbito del pensar.

El saber, para Zambrano, representa lo velado, la comarca de lo casi inefable, eso que apenas podemos balbucear a través del lenguaje, en tanto sistema racional. El pensar, por otra parte, tiende a performar una acción que se despliega hacia el futuro, mientras que el saber es experiencia acumulada, es pasado y es acción eminentemente práctica (Zambrano, 2016). Al respecto, la filosofía moderna, nos señala Zambrano, ha articulado una distancia infranqueable entre el saber y el pensar y ha normalizado como fuentes de supuesto saber solamente a aquellas experiencias traducibles al lenguaje lógico (Bundgård, 2009). 
Para la pensadora, tanto el saber cómo el pensar son, en última instancia, dos formas de relacionarse con lo existente y, para ella, la relación con lo que existe implica, en primerísimo lugar, la experiencia de familiaridad de trato con la totalidad del ser, de modo que tal experiencia tienda a modificar todo lo que es, al desatar una suerte de, lo que podríamos llamar, "revelación por saber experiencial". Sobre este punto del pensamiento de María Zambrano, la estudiosa Teresa Rocha Barco (1998) explica que:

Esta experiencia primordial es previa al pensamiento sistemático (a la razón teórica) y sólo puede ser captada por el momento poético de la razón, el único capaz de hacer posible la experiencia del ser propio del hombre (sin la pretensión de encerrarla en la estructura de un sistema): el fluir inagotable de la experiencia como unidad cada vez más íntima de vida y pensamiento; una unidad que modifica a ambos: éste se hace abierto e inacabable, aquélla adquiere su plenitud en éste. ( $\mathrm{p}$. 15)

Respecto a ese nivel de sabiduría experiencial profunda, es necesario y urgente, según la pensadora veleña, encontrar una vía para que el saber conjugue, sintetice y aprehenda todas las dimensiones del existir; sobre todo aquellas que, por no ser estrictamente abarcables desde la lógica del pensar, han sido olvidadas y menospreciadas. Marginación que se hace más patente respecto a las dimensiones ligadas al ámbito del sueño, la intuición, el inconsciente, el delirio y la locura (Foucault, 1986; Zambrano, 2011a).

\section{Conclusiones}

En este apartado y a la luz de lo expuesto, es posible proponer algunas consideraciones que más que pretender "cerrar" las nociones desarrolladas, son planteadas como balances transitorios, abiertos claramente a ser mejorados.

En relación al lenguaje religioso, en sus diferentes modos de uso, dado que quien habla esta inevitablemente implicado en lo dicho, se evidencia que el pensamiento de María Zambrano comporta el hecho de que ella fue testigo y protagonista de importantes momentos históricos de su nación, en particular, y de la historia de occidente, en general, durante buena parte del siglo XX. Especialmente significativas, en ello, parecen sus experiencias de mujer errante y su largo exilio. Además, se percibe que, dadas las características particulares de su obra y su pensamiento, la autora fue mantenida en una cierta marginalidad respecto del canon filosófico. Tal implicación entre la persona, su obra y su recepción canónica, más allá de la figura de la pensadora veleña, puede orientar a valorar positivamente las posibilidades comprensivas de estudios, de diversos campos y disciplinas, que contemplen la integración de las perspectivas biográficas junto a las eminentemente teóricas.

Por otra parte, asumiendo que Deus semper maior que nuestros intentos de aprehensión, a partir de la alta valoración que Zambrano concede al saber poético, en tanto posibilidad privilegiada de aprehensión creativa, se abre una posible veta de actividad teológica y filosófica, de naturaleza comprensivo-creativa, sostenida por la racionalidad poética donde eventualmente la verdad del ser no surgiría como asombro o pregunta sino que como revelación. Esta alternativa podría transformarse en razón de posibilidad de desarrollos disciplinares que acentúen la narratividad, la poética $y$, ante todo, la expresividad por sobre la lógica eminentemente racional. Más específicamente a partir de la 
distinción que María Zambrano establece entre "saber" y "pensar", se abre una posible veta que, a falta de otro concepto, se puede denominar como "conocimiento de y en penumbras". Un conocimiento vecino a la comarca de lo inefable, a eso que apenas podemos balbucear a través del lenguaje. Esto configuraría una alternativa de conocimiento "débil", cuya opacidad intrínseca supone abandonar la arrogancia, la "luminosidad encandilante" y la pretensión de totalidad que llegaron a caracterizar a la razón instrumental en occidente.

Como condición previa para que las alternativas señaladas lleguen a ser viables y fructíferas es necesario, según la pensadora veleña, recobrar la potencia elocutiva de la palabra misma para que, una vez recobrada ésta, poder encontrar y decir una vía que conjugue, sintetice y aprehenda todas las dimensiones del existir; sobre todo aquellas que, por no ser estrictamente abarcables desde la lógica, han sido más olvidadas y menospreciadas.

Finalmente, en la línea de allegar el pensamiento de María Zambrano hacia nuestro continente, específicamente hacia el pensamiento del filósofo argentino Rodolfo Kusch, es posible encontrar nociones de éste que guardan cierto "parecido de familia" con el pensamiento zambraniano (Wittgenstein, 1997). Concretamente es posible relacionar el concepto de "saber" que propone Zambrano con el concepto kuscheano de "razón seminal", entendido como la manifestación de saber que desarrollan los pueblos originarios y los estratos populares, más próximos al mundo-de-la-vida. En sus textos "La seducción de la barbarie", "América profunda" y "Geocultura del hombre americano", Kusch señala en detalle la naturaleza y alcances de tal aprehensión intuitiva desplegada por el pensamiento popular, parámetros a los que llama "aciertos fundantes". A tales aciertos, el pensador argentino los concibe incorporados a la cultura popular americana, en la que actúan como base del lenguaje, la canción folklórica y los refranes, entre otros posibles soportes -tales serían manifestaciones de la palabra poética desplegada, en el decir de Zambrano-. A tal sustrato de sabiduría, el pensador argentino lo caracteriza, a lo largo de su obra, a partir de la noción de lo arcaico o antiguo y, preferentemente, a partir de la noción de "pensamiento seminal" (Kusch, 2000).

La noción de lo seminal en Kusch también se percibe como dada en un cierto contrapunto, pues destaca la contraposición entre dos modos de pensar y vivir: uno occidental, caracterizado como "causal", y otro indígena, popular y endémico, identificado como "seminal". Donde lo seminal, lo arcaico y lo antiguo se contrastan y, en varios sentidos, se oponen con lo causal, lo moderno y lo actual. Es interesante recordar, en este punto, en un esfuerzo zambraniano de recobrar la fuerza elocutiva del término, que "seminal" remite al latín semen, seminis, de la familia etimológica de sembrar, que se puede traducir como "semilla" y que hace referencia al origen, al germen y a lo originante; en otras palabras, remite a aquello que procura crecer desde la tierra, en esta tierra (Kusch, 2000: 491-504). Respecto a ello, es posible concebir que la "razón seminal", en su propia especificidad geográfica y capacidad de elocución, es manifestación latinoamericana de aquello que la pensadora española llamó "razón poética", cuya propuesta y justificación es, a todas luces, uno de los mayores aportes de María Zambrano a la reflexión contemporánea. 


\section{Referencias Bibliográficas}

Acero Fernández, J. J. (1985). Filosofía y análisis del lenguaje (Vol. 33, Historia de la filosofía). Madrid: Cincel.

Amara, F., y Zappi, S. (2018). Ni putas ni sumisas (Feminismos) (M. Martínez Solimán, Trad.). Madrid: Cátedra.

Asensi Pérez, M. (1998). Historia de la teoría de la literatura (Vol. 1, Humanidades Literatura). Valencia: Tirant lo Blanch.

Balza Múgica, I. (2000). Tiempo y escritura en María Zambrano (Vol. 15, Cizaña baja al ágora). Bilbao: Iralka. https://bit.ly/2Koc9jp

Beevor, A. (2005). La guerra civil española (G. Pontón, Trad.). Barcelona: Critica.

Bundgård, A. (2005). "La placenta de sombra" de la poesía tres calas en el humanismo poético de María Zambrano. San Juan de la Cruz, Antonio Machado y Emilio Prados. En J. L. Mora García y S. M. Moreno Yuste (Coords.), Pensamiento y palabra en recuerdo de María Zambrano (1904-1991): Contribución de Segovia a su empresa intelectual (pp. 123-136). Valladolid: Junta de Castilla y León, Consejería de Cultura y Turismo.

Bundgård, A. (2009). Un compromiso apasionado: María Zambrano: una intelectual al servicio del pueblo (1928-1939). Madrid: Trotta.

Chomsky, N. (1973). El lenguaje y el entendimiento (2a ed., Vol. 314, Colección Biblioteca Breve. Ciencias Humanas) (J. Ferraté, Trad.). Barcelona: Seix Barral.

Conesa Ferrer, F. S., y Nubiola Aguilar, J. (2012). Filosofía del lenguaje. Barcelona: Herder.

Cordua Sommer, C. (1997). Wittgenstein: reorientación de la filosofía. Santiago: Dolmen. https://bit.ly/38mb4Rk

Correa Schnake, F. (2012). Una propuesta estructural de lectura de la trilogía teologal de Xavier Zubiri (Vol. 4, Anales de la Facultad de Teología). Santiago: Pontificia Universidad Católica de Chile.

Eco, U. (1992). Los límites de la interpretación (Vol. 214, Palabra en el tiempo) (H. Lozano Miralles, Trad.). Barcelona: Lumen.

Elíade, M. (1991). Mito y realidad (L. Gil, Trad.). Barcelona: Labor. https://bit.ly/2KDUZya

Elíade, M. (2000). Tratado de historia de las religiones: morfología y dialéctica de lo sagrado (3a ed., Fenomenología e historia de las religiones) (A. Medinaveitia, Trad.). Madrid: Cristiandad.

Escandell Vidal, M. V. (2006). Introducción a la pragmática (2a ed., Lingüística). Barcelona: Ariel.

Ferris, J. L. (2009). Miguel Hernández: pasiones, cárcel y muerte de un poeta (Argos. Biografía). La Habana: Arte y Literatura. 
Fink, E. (2000). La filosofía de Nietzsche (A. Sánchez Pascual, Trad.). Madrid: Alianza).

Foucault, M. (1986). Historia de la locura en la época clásica (J. J. Utrilla, Trad.). México: Fondo de Cultura Económica.

Goodman, N. (1990). Maneras de hacer mundos (Vol. 30, La balsa de la Medusa) (C. Thiebaut, Trad.). Madrid: Visor. https://bit.ly/2LVOsj3

Habermas, J. (1989). Teoría de la acción comunicativa (Vol. 1) (M. Jiménez Redondo, Trad.). Buenos Aires: Taurus.

Heidegger, M. (1997). Ser y tiempo (El Saber y la cultura., Temas de filosofía.) (J. E. Rivera C., Trad.). Santiago: Universitaria.

Heidegger, M. (2001). Carta sobre el humanismo (2a ed., Vol. 4414, Libro de bolsillo) (H. Cortés y A. Leyte, Trad.). Madrid: Alianza.

Hernández, M. (1984). Poemas varios 1933-1934. En su Obra poética completa (2a ed., Vol. 89, Alianza tres, pp. 125-293). Madrid: Alianza.

Kusch, R. (2000). Obras Completas (Vol. 1). Rosario: Fundación Ross.

Laguna García, R. (2015). Habitaciones del pensamiento: la ciudad en la filosofía de María Zambrano. México: Universidad Nacional Autónoma de México, Facultad de Filosofía y Letras.

Lemm, V. (2010). La filosofía animal de Nietzsche: Cultura, política y animalidad del ser humano (Vol. 27, Colección Pensamiento contemporáneo) (D. Rosello, Trad.). Santiago: Universidad Diego Portales.

Lizaola Monterrubio, J. (2008). Lo sagrado en el pensamiento de María Zambrano (Vol. 36, Filosofía y cultura contemporánea). México, DF: Universidad Nacional Autónoma de México.

Montero Díaz, M. (2009). La conquista del espacio público: mujeres españolas en la universidad (1910-1936) (Estudios sobre la mujer). Madrid: Minerva.

Moreno Sanz, J. (1994). Cronología. En M. Zambrano (Autora), La razón en la sombra: antología (Vol. 59, Libros del tiempo, pp. 607-629). Madrid: Siruela.

Nietzsche, F. W. (1985). El nacimiento de la tragedia o Grecia y el pesimismo (Vol. 456, El libro de bolsillo) (A. Sánchez Pascual, Trad.). Madrid: Alianza.

Ortega Muñoz, F. J. (1992). María Zambrano: su vida y su obra (Cuadernos de Puertanueva. Arte y pensamiento.). Málaga: Consejería de Educación y Ciencia, Delegación Provincial.

Otto, R. (2001). Lo santo: Lo racional y lo irracional en la idea de Dios (Vol. 793, Libro de bolsillo. Humanidades) (F. Vela, Trad.). Madrid: Alianza.

Pulgar Castro, R. (2015). María Zambrano y el sentido religioso de la existencia. Atenea (Concepción), (511), 105-123. https://doi.org/10.4067/s0718-04622015000100006 
Platón. (1986). República (Vol. 4, Diálogos) (C. Eggers Lan, Trad.). Madrid: Gredos. https://bit.ly/37Bd9JY

Quezada, J. (2010). Poesía y prosa de Gabriela Mistral: Una antología fundamental. En G. Mistral (Autora), Antología de poesía y prosa de Gabriela Mistral (2a ed., Tierra Firma, pp. 920). Santiago: Fondo de Cultura Económica.

Rahner, K. (2002). Escritos de teología (4a ed., Vol. 4) (J. Molina, Trad.). Madrid: Cristianidad.

Robles Carcedo, L. (1991). A propósito de 3 cartas de María Zambrano a Ortega. Philosophica Malacitana, 4, 231-239

Rocha Barco, T. (Ed.). (1998). María Zambrano: La razón poética o la filosofía (Ventana abierta.). Madrid: Tecnos.

Romero González, S. (2014). Escritos circunstanciales: pensamiento situado (Tierra Elqui). La Serena: Albricias Ediciones

Romero González, S. (2017). Filosofía desde la caleta: algunas formar de filosofar. La Serena: Albricias Ediciones

Schaeffer, J. (2012). Arte, objetos, ficción, cuerpo: Cuatro ensayos sobre estética (Colección Pasajes) (R. Ibarlucia, Trad.). Buenos Aires: Biblos.

Wittgenstein, L. (1997). Comentarios sobre La rama dorada (2a ed., Vol. 43, Cuadernos) (J. Esquivel, Trad.). México, DF: Universidad Nacional Autónoma de México.

Wittgenstein, L. (2016). Investigaciones filosóficas (Estructuras y procesos) (J. Padilla Gálvez, Trad.). Madrid: Trotta.

Zambrano, M. (Febrero 4, 1952). [Carta a Gabriela Mistral]. El Vedado Calle N²12, La Habana, Cuba [Manuscrito]. https://bit.ly/2LQzfQ6

Zambrano, M. (1984). Andalucía: sueño y verdad. Granada: Andaluzas Unidas.

Zambrano, M. (1987). A modo de autobiografía. Anthropos, (70-71), 69-93.

Zambrano, M. (1991) Los bienaventurados (2a ed.). Madrid: Siruela.

Zambrano, M. (1998) Los intelectuales en el drama de España y escritos de la guerra civil. Madrid: Trotta.

Zambrano, M. (2003). La razón en la sombra: antología. Madrid: Siruela.

Zambrano, M. (2004). Los sueños y el tiempo (2a ed., Vol. 10, Biblioteca de ensayo). Madrid: Siruela.

Zambrano, M. (2007). El hombre y lo divino (Vol. 3, Heteroclásica/Pensar en español). México, DF: Fondo de Cultura Económica.

Zambrano, M. (2008). Hacia un saber sobre el alma (Alianza literaria). Madrid: Alianza. 
Zambrano, M. (2009). Las palabras del regreso (Vol. 642, Letras hispánicas). Madrid: Cátedra.

Zambrano, M. (2011a). Claros del bosque (Vol. 692, Letras hispánicas). Madrid: Cátedra.

Zambrano, M. (2011b). Escritos sobre Ortega (Colección Estructuras y procesos, Serie Filosofía). Madrid: Trotta.

Zambrano, M. (2015). Obras completas (Vol. 1). Barcelona: Galaxia Gutenberg.

Zambrano, M. (2016). Filosofía y poesía (6a ed.). México, DF: Fondo de Cultura Económica.

Zea Aguilar, L. (1987). Filosofía de la historia americana. México, DF: Fondo de Cultura Económica.

Zubiri, X. (1999). Primeros escritos (1921-1926). Madrid: Alianza.

Zubiri, X. (2003). Inteligencia sentiente (Vol. 3). Madrid: Alianza.

Zubiri, X. (2004). Naturaleza, historia, Dios (12a ed.). Madrid: Alianza.

\section{Para citar este artículo bajo Norma APA 7a ed. \\ Santibáñez Rodríguez, N. (2020). Razón poética, revelación y saber: aproximaciones al pensamiento religioso de María Zambrano. Cuadernos de teología - Universidad Católica del Norte (En línea), 12, e4094, https://doi.org/10.22199/issn.0719-8175- 2020-0007}

\section{DOI}

Copyright del articulo: @2020 Nelson Santibáñez

Este es un artículo de acceso abierto, bajo licencia Creative Commons BY 4.0. 